\title{
Equilibrium and kinetic Si isotope fractionation factors and their implications for Si isotope distributions in the Earth's surface environments
}

\author{
Hong-tao He ${ }^{1,2} \cdot$ Siting Zhang ${ }^{1}$ Chen $\mathrm{Zhu}^{3} \cdot$ Yun Liu ${ }^{1}$
}

Received: 15 May 2015/Revised: 26 October 2015/Accepted: 27 October 2015/Published online: 20 November 2015

(C) Science Press, Institute of Geochemistry, CAS and Springer-Verlag Berlin Heidelberg 2015

\begin{abstract}
Several important equilibrium Si isotope fractionation factors among minerals, organic molecules and the $\mathrm{H}_{4} \mathrm{SiO}_{4}$ solution are complemented to facilitate the explanation of the distributions of Si isotopes in Earth's surface environments. The results reveal that, in comparison to aqueous $\mathrm{H}_{4} \mathrm{SiO}_{4}$, heavy $\mathrm{Si}$ isotopes will be significantly enriched in secondary silicate minerals. On the contrary, quadra-coordinated organosilicon complexes are enriched in light silicon isotope relative to the solution. The extent of ${ }^{28} \mathrm{Si}$-enrichment in hyper-coordinated organosilicon complexes was found to be the largest. In addition, the large kinetic isotope effect associated with the polymerization of monosilicic acid and dimer was calculated, and the results support the previous statement that highly ${ }^{28} \mathrm{Si}$ enrichment in the formation of amorphous quartz precursor contributes to the discrepancy between theoretical calculations and field observations. With the equilibrium $\mathrm{Si}$ isotope fractionation factors provided here, $\mathrm{Si}$ isotope distributions in many of Earth's surface systems can be
\end{abstract}

Electronic supplementary material The online version of this article (doi:10.1007/s11631-015-0079-x) contains supplementary material, which is available to authorized users.

Yun Liu

liuyun@vip.gyig.ac.cn

Hong-tao $\mathrm{He}$

hehongtao0818@yeah.net

1 State Key Laboratory of Ore Deposit Geochemistry, Institute of Geochemistry, Chinese Academy of Sciences,

Guiyang 550081, China

2 University of Chinese Academy of Sciences, Beijing 100049, China

3 Department of Geological Sciences, Indiana University, Bloomington, IN 47405, USA explained. For example, the change of bulk soil $\delta^{30} \mathrm{Si}$ can be predicted as a concave pattern with respect to the weathering degree, with the minimum value where allophane completely dissolves and the total amount of sesquioxides and poorly crystalline minerals reaches their maximum. When, under equilibrium conditions, the well-crystallized clays start to precipitate from the pore solutions, the bulk soil $\delta^{30} \mathrm{Si}$ will increase again and reach a constant value. Similarly, the precipitation of crystalline smectite and the dissolution of poorly crystalline kaolinite may explain the $\delta^{30} \mathrm{Si}$ variations in the ground water profile. The equilibrium $\mathrm{Si}$ isotope fractionations among the quadracoordinated organosilicon complexes and the $\mathrm{H}_{4} \mathrm{SiO}_{4}$ solution may also shed light on the $\mathrm{Si}$ isotope distributions in the Si-accumulating plants.

Keywords Si isotopes - Equilibrium fractionation factor . Quantum chemistry calculation · Cluster model · Kinetic isotope effect

\section{Introduction}

The silicon element, only second in abundance to oxygen in Earth's crust, is one of the most dominant constituents in silicates. Since Si is a typical non-redox element and often exists in a stable tetrahedron, the variations of its isotopic composition in Earth's various surface systems are small, no more than 11.8 per mil (Opfergelt and Delmelle 2012). In comparison, there are no or only slight $\mathrm{Si}$ isotope fractionations occurring in the formations of the primary silicate minerals (Savage et al. 2011). With the rapid progress of high-resolution analytical instruments including ICP-MS and SIMS, slight variations of Si isotopic compositions can be detected. Therefore, the $\mathrm{Si}$ isotope compositions in 
many of Earth's surface systems, including soils, rivers, oceans, silicon-accumulating algae and high plants, have all been investigated (Basile-Doelsch et al. 2005; Ding et al. 2008, 2009; Georg et al. 2007, 2009; Hughes et al. 2013; Ziegler et al. 2005). One can refer to the comprehensive reviews of $\mathrm{Si}$ isotope geochemistry in Opfergelt and Delmelle (2012). In brief summary, river water and seawater have positive $\delta^{30} \mathrm{Si}$ signals, but ground water has negative ones. In addition, $\delta^{30} \mathrm{Si}$ values of the ground water decrease with increasing water-rocks interaction and with increasing weathering degree. However, a concave pattern was identified in the $\mathrm{Si}$-accumulating plants including rice, bamboo, and bananas: the $\delta^{30} \mathrm{Si}$ values decrease from root to stem and increase from stem to shoots (Ding et al. 2008, 2009; Georg et al. 2009; Ziegler et al. 2005).

There are disagreements on the explanation for the $\mathrm{Si}$ isotope signals in Earth's surface systems. For example, it has been argued that the dissolution of primary silicate minerals will preferentially release light $\mathrm{Si}$ isotopes to cause the solution to have negative $\delta^{30} \mathrm{Si}$ values. This explanation is untenable on a large time scale ( $\mathrm{He}$ and $\mathrm{Liu}$, 2015). Another point of disagreement is the employment of the Rayleigh model for the interpretation of experimental $\mathrm{Si}$ isotope data, especially for complicated and open systems. The deduced $\mathrm{Si}$ isotope equilibrium fractionation factors by such models at ambient temperatures between the clay and the solution $\Delta^{30} \mathrm{Si}_{\text {clay-solution }}=-1.5 \%$ o $(\mathrm{Ge}$ org et al. 2007) and $-2.05 \%$ (Hughes et al. 2013) obviously deviate from the theoretical predictions, which reveals that stiffer chemical bonds will enrich heavier isotopes, i.e., the precipitated minerals will preferentially incorporate heavy isotopes relative to the aqueous $\mathrm{H}_{4} \mathrm{SiO}_{4}$ due to their shorter $\mathrm{Si}-\mathrm{O}$ bonds.

Moreover, Ziegler et al. (2005) suggested that it was the continuous leaching of the ${ }^{30} \mathrm{Si}$-entriched pore water during the dissolution-reprecipitation processes that resulted in the gradual decrease of soil bulk $\delta^{30} \mathrm{Si}$ with the weathering degree. Considering that this part of the pore water likely discharges into the groundwater, if the leached pore water is always enriched in ${ }^{30} \mathrm{Si}$, the sole consequence will be extreme ${ }^{30} \mathrm{Si}$-enrichment of the ground water relative to the pore water, which is not in consistent with our current observations. So if in some dissolution-reprecipitation processes the leached pore water converts into ${ }^{28} \mathrm{Si}$-enrichment from ${ }^{30} \mathrm{Si}$-enrichment, this contradiction could be figured out.

To clarify those issues of contention, the equilibrium $\mathrm{Si}$ isotope fractionation factors for the silicate minerals, orthosilicic acid solution and organosilicon complexes were calculated using a newly proposed cluster-modelbased quantum chemistry method (Liu 2013). Albite was chosen as a candidate for its stability in diagenesis. Kaolinite was selected for its ubiquity in weathering environments as a mature weathering product. A few 4-, 5-, or 6-coordinated organosilicon complexes related to the metabolic process of $\mathrm{Si}$ in plants were also calculated to explore the $\mathrm{Si}$ isotope fractionations in plants. Also, the polymerization of monosilicic acid and dimer when approaching the precipitation of amorphous silica was designed to calculate the kinetic isotope effect.

\section{Theory and calculation}

\subsection{Bigeleisen and Mayer equation}

The works by Bigeleisen and Mayer (1947) and Urey (1947) about the equilibrium constant calculation for isotopic exchange reactions have established the base of theoretical and computational geochemistry. Specifically, for an ideal single-atom-substitution system, where the compound is exchanging isotopes with the atom, the reaction equation is shown as:

$A X^{\prime}+X=A X+X^{\prime}$

Element $\mathrm{X}$ has two isotopes, with the primed one denoting the light isotope. The equilibrium constant $\mathrm{K}$ can be depicted as the quotient of the partition functions of the products and reactants as follows:

$K=\frac{Q_{A X} Q_{X^{\prime}}}{Q_{A X^{\prime}} Q_{X}}$

The partition function comprises of the transitional partition function $\mathrm{Q}_{\text {trans }}$, rotational partition function $\mathrm{Q}_{\text {rot }}$, vibrational partition function $Q_{\text {vib }}$ and electronic partition function $Q_{\text {elec }}$. For light elements, the electronic energy of a compound after isotope substitution does not change. So the electronic partition function can be canceled out.

The theorem of Teller and Redlich (1935) is often employed to simplify the calculation of the equilibrium constant, K. K can be expressed as,

$$
K=\frac{\sigma^{\prime}}{\sigma} \prod^{3 n-6} \frac{u}{u^{\prime}}\left(\frac{e^{-\frac{u}{2}}}{e^{-\frac{u^{\prime}}{2}}}\right)\left(\frac{1-e^{-u^{\prime}}}{1-e^{-u}}\right)
$$

where $u=\mathrm{hc} \omega / \mathrm{kT}$, with $\mathrm{h}$ denoting the Plank constant; $\sigma$, the symmetry factor; $\mathrm{k}$, the Boltzmann constant; $\mathrm{T}$, absolute temperature in $\mathrm{K}$; c, velocity of light; and $\omega$, the harmonic frequencies in $\mathrm{cm}^{-1}$.

The Reduced Partition Function Ratio (RPFR) is defined as:

$R P F R=\prod^{3 n-6} \frac{u}{u^{\prime}}\left(\frac{e^{-\frac{u}{2}}}{e^{-\frac{u^{\prime}}{2}}}\right)\left(\frac{1-e^{-u^{\prime}}}{1-e^{-u}}\right)$.

Herein, $\mathrm{K}$ is equal to the isotopic fractionation factor $\alpha$. Given the RPFRs of a pair of minerals in equilibrium, $\alpha$ can be derived from the ratio of their RPFRs. 


\subsection{Kinetic isotope effect}

Bigeleisen and Wolfsberg (1958) introduced the transition state theory to tackle the kinetic isotope effect in chemical reactions. It is assumed that the isotope exchange equilibrium between the reactants and the transition state complex is reached and that the transition state complexes with different isotopes have the identical probability of forming products. Therefore, the isotope fractionation between the products and reactants is determined by the isotope exchange equilibrium between the reactants and the transition state complex. The Kinetic Isotope effect (KIE) is defined as the ratio of rate constants for light and heavy isotopes in formation of the transition state complex:

$K I E=\frac{k_{L}}{k_{H}}=\frac{R P F R_{\text {react }}}{R P F R_{t s}}$

where $\mathrm{k}_{\mathrm{L}}$ and $\mathrm{k}_{\mathrm{H}}$ are the rate constants for light and heavy isotopes, respectively, and $\mathrm{RPFR}_{\text {react }}$ and $\mathrm{RPFR}_{\mathrm{ts}}$ are the reduced partition function ratios for the reactant and transition state complex. In the calculation for $\mathrm{RPFR}_{\mathrm{ts}}$, one of the vibrational degrees of freedom along the path of decomposition is missing from the vibrational partition function. Finally, $\mathrm{RPFR}_{\mathrm{ts}}$ takes the form:

$\operatorname{RPFR}_{t s}=\frac{v_{L}^{\neq}}{v_{L}^{\prime \neq}} \prod^{3 n-7} \frac{u^{\neq}}{u^{\prime \neq}}\left(\frac{e^{-\frac{u^{\prime}}{2}}}{e^{-\frac{u^{\prime} \neq}{2}}}\right)\left(\frac{1-e^{-u^{\prime} \neq}}{1-e^{-u \neq}}\right)$

where $v_{\mathrm{L}}^{\neq}$is the imaginary frequency along the path of decomposition.

\subsection{Geometry optimization}

The Volume Variable Cluster Model (VVCM) method (Liu 2013) was employed to optimize the mineral structures. One can refer to the detailed procedure in He and Liu (2015). Herein, to express it concisely, the cluster is built from three dimensional crystal structures established by X-ray diffraction or neutron diffraction data. Virtual point charges were added to the outermost darling bonds to keep the neutrality of the whole cluster. By adjusting the distance between point charges and the outermost atoms, different stable mineral structures were sought out, from which the calculated structures with the least deviation from the experimental structures and the lowest electronic energy were selected for the calculation of the RPFR values. All geometry optimization was implemented with the GAUSSIAN09 software package (Frisch et al. 2010). The hybrid DFT method at B3LYP/6-311G(2df) level was employed to optimize the 3-dimensional structures of the silicate minerals (Becke 1993). As for the hydrogen-containing minerals and orthosilicic acid solution, an extra set of $\mathrm{p}$ functions was added to this level.

\section{Results}

\subsection{Optimized mineral structures}

The optimized mineral structures tabulated in Table 1 and the Supplementary data are consistent with experimental data. The mismatches are in the order of per mil.

\section{$3.2 \Delta^{30} \mathrm{Si}_{\text {mineral-mineral }}$}

We used weighted-RPFR values for kaolinite and albite because they have more than one $\mathrm{Si}$ site in their structures. Apparently, quartz is enriched in the heavy $\mathrm{Si}$ isotope relative to kaolinite and albite (Fig. 1), which is qualitatively consistent with results of Méheut et al. (2009) and Méheut and Schauble (2014). The enrichment order quartz $>$ albite $>$ kaolinite is consistent with the order of the gradually prolonged average $\mathrm{Si}-\mathrm{O}$ bond length in these minerals. Although in good agreement with the previous results between quartz and albite, there are large discrepancies in the cases of "quartz vs. kaolinite" and "albite vs. kaolinite"; much smaller $\mathrm{Si}$ isotope fractionations are predicted here (Fig. 1).

\section{$3.3 \Delta^{30} \mathrm{Si}_{\text {solid-solution }}$}

Based on the RPFR value of the $\mathrm{H}_{4} \mathrm{SiO}_{4}$ solution calculated by the identical level (i.e., 1.0718, from $\mathrm{He}$ and Liu (2015)), kaolinite tends to be enriched in ${ }^{30} \mathrm{Si}$ if it is in equilibrium with the solution (Fig. 2). However, the field observation results diverge. The smectite result (Georg et al. 2009) is smaller than our kaolinite result, which is reasonable as the average $\mathrm{Si}-\mathrm{O}$ bond length in smectite is longer. However, the field observation results of kaolinite

Table 1 Comparisons of average $\mathrm{Si}-\mathrm{O}$ bond length between optimized mineral structure and experimental data

\begin{tabular}{lllc}
\hline Minerals & Calculated $(\AA)$ & Experimental $(\AA)$ & Error $(\%)$ \\
\hline Quartz & 1.613 & 1.610 & 1.9 \\
Kaolinite_Si1 & 1.621 & $1.621^{\mathrm{a}}, 1.620^{\mathrm{b}}$ & 0.0 \\
Kaolinite_Si2 & 1.618 & $1.614^{\mathrm{a}}, 1.615^{\mathrm{b}}$ & 2.5 \\
Albite_Si1m & 1.609 & 1.607 & 1.2 \\
Albite_Si2m & 1.623 & 1.616 & 4.3 \\
Albite_Si2o & 1.619 & 1.615 & 2.5 \\
Aqueous $\mathrm{H}_{4} \mathrm{SiO}_{4}$ & 1.636 & 1.639 & -1.9
\end{tabular}

Experimental structures are listed to be compared to the calculated ones (quartz: Hazen et al. 1989; kaolinite: (a) Bish and Von Dreele 1989 and (b) Neder et al. 1999; albite: Harlow and Brown 1980; aqueous $\mathrm{H}_{4} \mathrm{SiO}_{4}$ : Rastsvetaeva et al. 2009). Initial structures of the kaolinite are extracted from the neutron powder diffraction data (Bish 1993). The optimized quartz and aqueous $\mathrm{H}_{4} \mathrm{SiO}_{4}$ solution are from He and Liu (2015) 

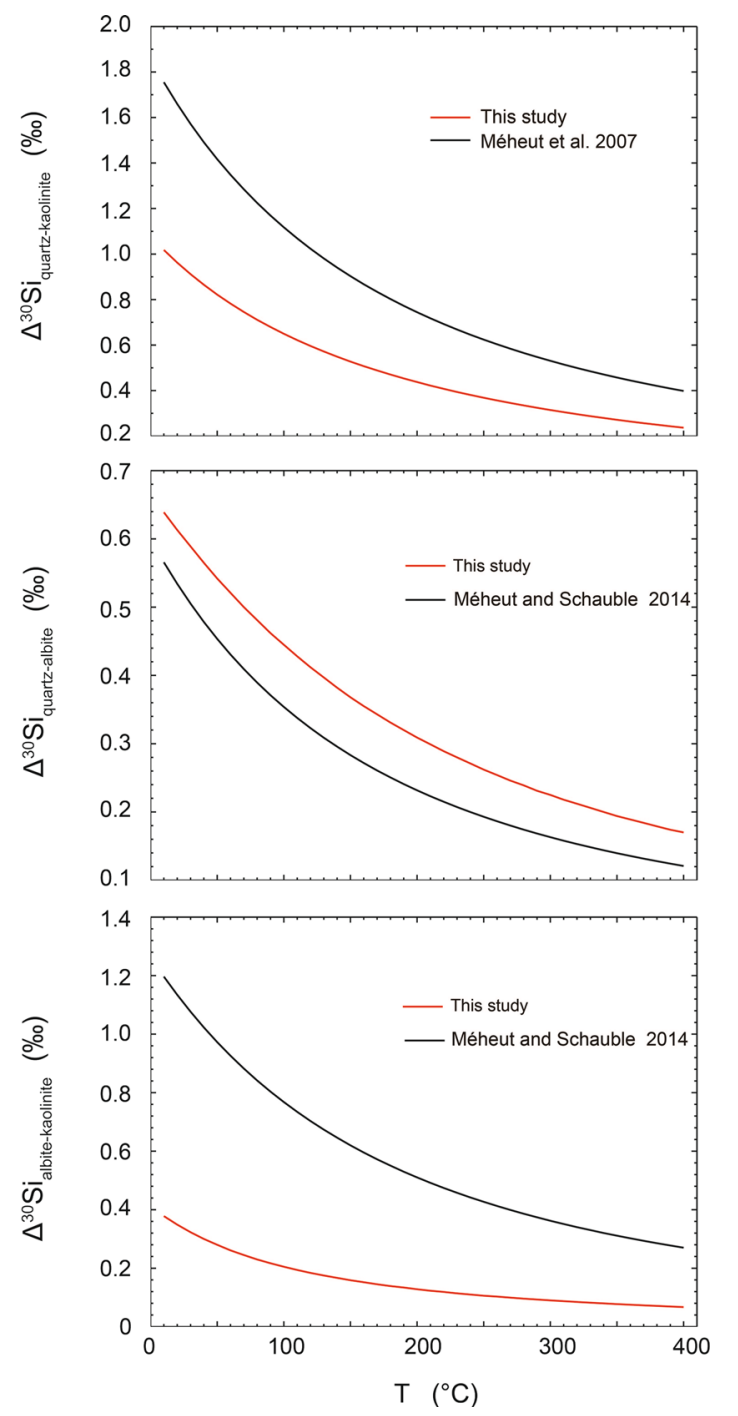

Fig. 1 Theoretical $\mathrm{Si}$ isotope equilibrium fractionations among several silicate minerals

(Georg et al. 2007) and 2:1 clay (Hughes et al. 2013) are in completely opposite directions. We will address these disagreements in Discussions.

The temperature dependencies of the equilibrium $\mathrm{Si}$ isotope fractionations between the minerals and the $\mathrm{H}_{4} \mathrm{SiO}_{4}$ solution can be found in Table 2. The results of Méheut et al. (2007) and Méheut and Schauble (2014) are also listed for comparison.

\section{$3.4 \Delta^{30} \mathrm{Si}_{\text {organosilicon complexes-H4SiO4 }}$}

We arbitrarily selected propanetriol to build the four-coordinated organosilicon complexes. In addition, the structures of the hyper-coordinated organosilicon complexes from Kubicki and Heaney (2003) were rebuilt. Figure 3 shows the optimized geometries of the organosilicon

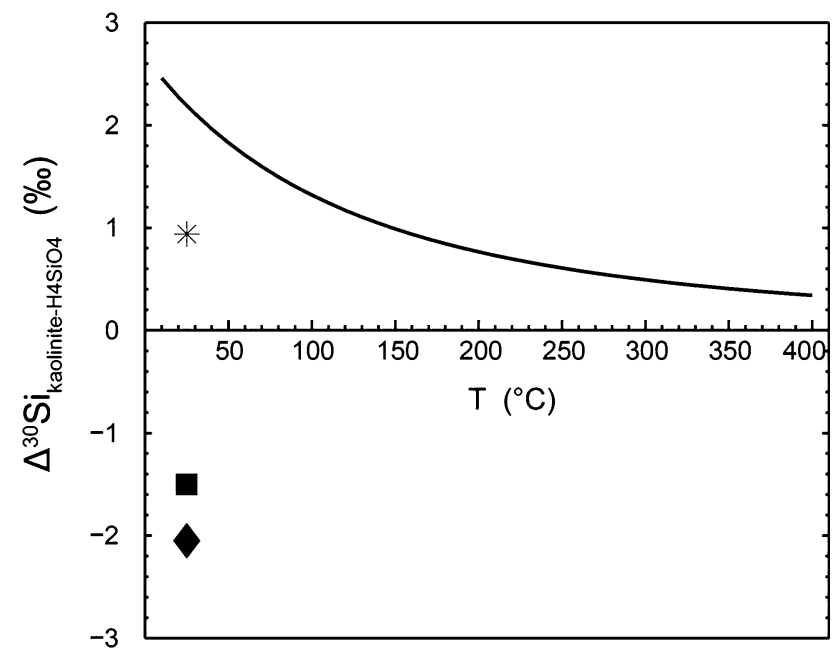

Fig. 2 Theoretical $\mathrm{Si}$ isotope equilibrium fractionation between kaolinite and aqueous $\mathrm{H}_{4} \mathrm{SiO}_{4}$ solution. Field observations from Georg et al. (2009) (smectite, star), Georg et al. (2007) (square) and Hughes et al. (2013) (diamond)

complexes we studied. Extremely large equilibrium Si isotope fractionations were found between the hyper-coordinated organosilicon complexes and the aqueous $\mathrm{H}_{4} \mathrm{SiO}_{4}$ at $298.15 \mathrm{~K}$, such as $-9.1 \%$ for the ${ }^{[5]} \mathrm{Si}$-disorbitol complex and $-19.2 \%$ for the ${ }^{[6]} \mathrm{Si}$-trisorbitol complex, whilst there are only moderate fractionations for the four-coordinated complexes, such as $-0.36 \%$ for the ${ }^{[4]} \mathrm{Si}$-propanetriol complex and $-0.92 \%$ for the ${ }^{[4]} \mathrm{Si}$ dipropanetriol complex.

\subsection{KIE in the polymerization of monosilicic acid and dimer}

He and Liu (2015) has calculated the KIE in the dimerization of monosilicic acid, 1.005. Recently, McIntosh (2013) indicated that there were two routes for monosilicic acid and dimer in basic solution to form trimer. Given the same mechanism, there must also be two routes for monosilicic acid and dimer to form trimer in neutral solution (Fig. 4). We have successfully searched out the transition states by synchronization transition quasi-Newton searching methods (i.e. the QST3 method in Gaussian09). The calculated activation energies and KIEs are shown in Table 3.

It should be noted that route 1 discriminates ${ }^{28} \mathrm{Si}$ in the formation of the transition state, with a KIE value, 0.999548 , whilst route 2 prefers ${ }^{28} \mathrm{Si}$ in the formation of transition state, with a KIE value, 1.010618. Given the same pre-exponential factor, the slightly low activation energy of route 2 indicates that, in the incorporation of monosilicic acid into the crystal lattice, the monosilicic acid molecule is selected to adjust geometric structure and 
Table 2 Fits of $1000 \ln \alpha$ based on the function

$\mathrm{ax}^{3}+\mathrm{bx}^{2}+\mathrm{cx}+\mathrm{d}$, with $\mathrm{x}=10^{6} / \mathrm{T}^{2}, \mathrm{~T}$ in $\mathrm{K}$

\begin{tabular}{llrrrr}
\hline Phases & Temperature $\left({ }^{\circ} \mathrm{C}\right)$ & $\mathrm{a}$ & $\mathrm{b}$ & $\mathrm{c}$ & $\mathrm{d}$ \\
\hline Quartz-Kaolinite & $0-400$ & 0.000078 & -0.0030 & 0.1057 & 0.0184 \\
Quartz-Kaolinite $^{\mathrm{a}}$ & $0-400$ & 0.000099 & -0.0045 & 0.1796 & 0.0230 \\
Quartz-Albite $_{\text {Quartz-Albite }}^{\mathrm{b}}$ & $0-400$ & 0.000059 & -0.0031 & 0.0801 & 0.0078 \\
Albite-Kaolinite $_{\text {Albite-Kaolinite }}^{\mathrm{b}}$ & $0-400$ & 0.000016 & -0.0010 & 0.0552 & 0.0039 \\
Quartz- $_{4} \mathrm{SiO}_{4}(\mathrm{aq})$ & $0-400$ & 0.000016 & 0.0001 & 0.0251 & 0.0114 \\
Albite- $\mathrm{H}_{4} \mathrm{SiO}_{4}(\mathrm{aq})$ & $0-400$ & 0.000045 & -0.0029 & 0.1236 & 0.0111 \\
Kaolinite- $_{4} \mathrm{SiO}_{4}(\mathrm{aq})$ & $0-400$ & -0.000073 & 0.0021 & 0.2650 & -0.0175 \\
\hline
\end{tabular}

${ }^{a}$ Méheut et al. (2007) data

${ }^{b}$ Fit of Méheut and Schauble (2014) data on x to lose a water molecule. At ambient temperature, the reaction rate of route 2 is 2.24 times of that of route 1 . The weighted average KIE value for the formation of amorphous silica is 1.0072. Although the experimental data deviate from the numerical calculations, they both show the positive temperature dependence (Fig. 5).

\section{Discussion}

\subsection{Plane-wave DFT method vs. VVCM method}

There are significant discrepancies between our Volume Variable Cluster Model (VVCM) calculations and some of the pseudo-potential based plane-wave DFT results (Méheut et al. 2007; Méheut and Schauble 2014) (Fig. 1). Here we compare the results of the geometry optimization and frequency of these two methods.

In the case of geometry optimization, pseudopotential plane-wave DFT methods can effectively reproduce cell parameters of silicates despite the large elongation of the average $\mathrm{Si}-\mathrm{O}$ bond; for example, $1.2 \%$ error for quartz and $1.4 \%$ error for phyllosilicates (i.e., clay minerals) (Balan et al. 2001), due to the shortcoming of the PBE functional employed in the calculations (Méheut et al. 2007; Méheut and Schauble, 2014). In comparison, the largest average $\mathrm{Si}-\mathrm{O}$ bond length error in our VVCM calculations is only $0.43 \%$ in all studied minerals (Table 1), showing the power of a large full-electron wavefunction (i.e., B3LYP/6-311G(2df,p)) used in the geometry optimization. In fact, the isotope effect highly depends on the local kinetic energy differences surrounding the atom of interest before/after isotope substitution; so to effectively reproduce the local experimental structure surrounding the atom of interest it is very important to calculate the isotope fractionation. In these cases, large deviations of the calculated structures of a pair of minerals from the experimental ones, especially disproportionate deviations, may exert a considerable influence on the $\mathrm{Si}$ equilibrium isotope fractionation calculations (cf. quartzkaolinite, albite-kaolinite, Méheut et al. 2007, Méheut and Schauble 2014). However, if the deviations from the experimental structures are by the identical extent, the influence of the structural uncertainty on the $\mathrm{Si}$ isotope equilibrium fractionation may be canceled as a systematic error (cf. quartz-albite, Méheut and Schauble 2014).

The essence of structural uncertainty is the uncertainty of harmonic frequency, which is an important parameter in calculating RPFR values. Méheut et al. (2009) pointed out that about $5 \%$ systematic errors in frequencies would bring about $10 \%$ relative errors in the calculation of $1000 \ln \alpha$ at low temperatures. Typically, the calculated harmonic frequencies are overestimated and a scaling factor smaller than unity is needed to calibrate the calculated frequencies. For a pair of minerals, whose structures deviate disproportionately from the experimental ones, it is difficult to determine a sole scaling factor. Therefore, in the calculations of the Si isotope fractionation factors, it seems safe to keep the calculated structures within the uncertainty of experimental data. Based on the discussion above, our results are reliable.

\section{2 $\mathrm{Si}$ isotope fractionation between clay and solution}

We provide equilibrium $\mathrm{Si}$ isotope fractionations between kaolinite and the solution at different temperatures (Fig. 2). Our calculation results are significantly larger than the field observations of Georg et al. (2007), (2009) and Hughes et al. (2013).

Because there was a much shorter average $\mathrm{Si}-\mathrm{O}$ bond

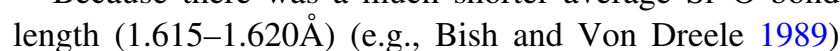
compared to that of smectite (1.635-1.645 $)$ (e.g., Gournis et al. 2008) for the smectite case (Georg et al. 
Fig. 3 Structures of organosilicon complexes: $\mathbf{a}$ and b are Si-containing complexes coordinated by propanetriol while $\mathbf{c}$ and $\mathbf{d}$ coordinated by sorbitol

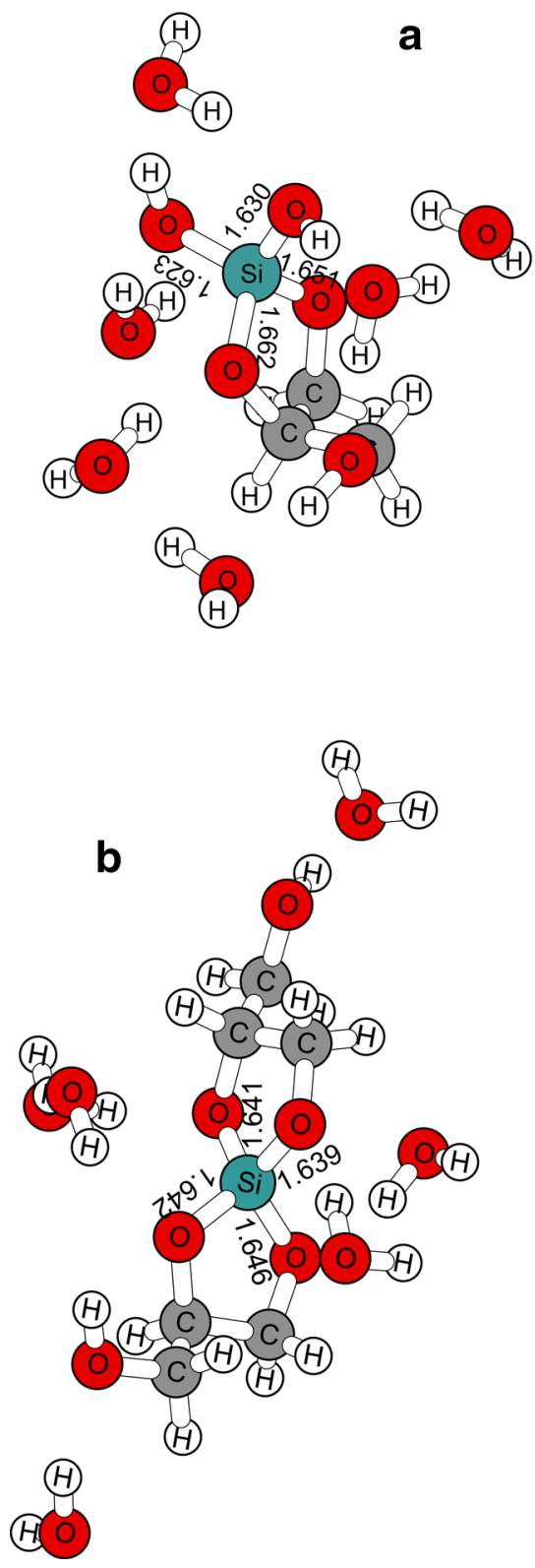

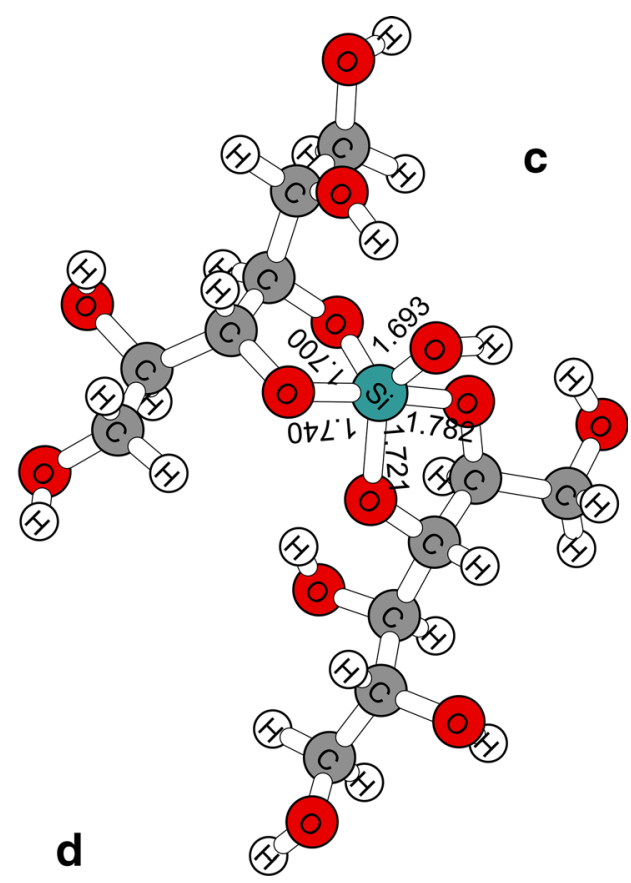

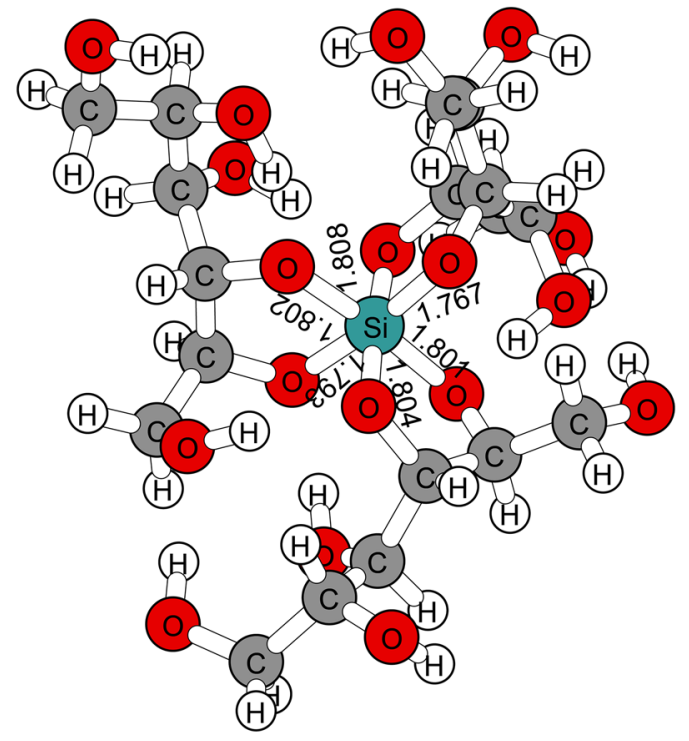

2009), kaolinite is expected to be enriched in heavier $\mathrm{Si}$ isotopes relative to smectite, as our calculations show.

The field observations of Georg et al. (2007) and Hughes et al. (2013) suggested that aqueous $\mathrm{H}_{4} \mathrm{SiO}_{4}$ enriched heavier $\mathrm{Si}$ isotopes than the clay minerals (Fig. 2), which were in obvious disagreement with the theoretical predictions. According to either the experimental data (Rastsvetaeva et al. 2009) or our quantum chemistry calculations, the average $\mathrm{Si}-\mathrm{O}$ bond length in aqueous $\mathrm{H}_{4} \mathrm{SiO}_{4}$ is longer than those in clay minerals (e.g., 1.639 vs. $1.62-1.63 \AA$ ), meaning aqueous $\mathrm{H}_{4} \mathrm{SiO}_{4}$ cannot enrich heavier $\mathrm{Si}$ isotopes than clay minerals if under an equilibrium condition. Those field observations actually reflected the "net" or "apparent" Si isotope fractionation between the river water and the clay minerals. However, it is not an equilibrium Si isotope fractionation factor for a single isotope exchange reaction. The clay mineral precipitating processes are very complicated, including the non-equilibrium processes and the formation of other Si-bearing compounds (e.g., organosilicon complexes). These affecting factors will lead to a large negative "apparent" isotope fractionation factor, as observed in field. With the equilibrium Si isotope fractionation factors provided here, we could further explore the molecular-level clay mineral precipitation mechanisms by distinguishing the equilibrium isotope fractionations from the other processes. 


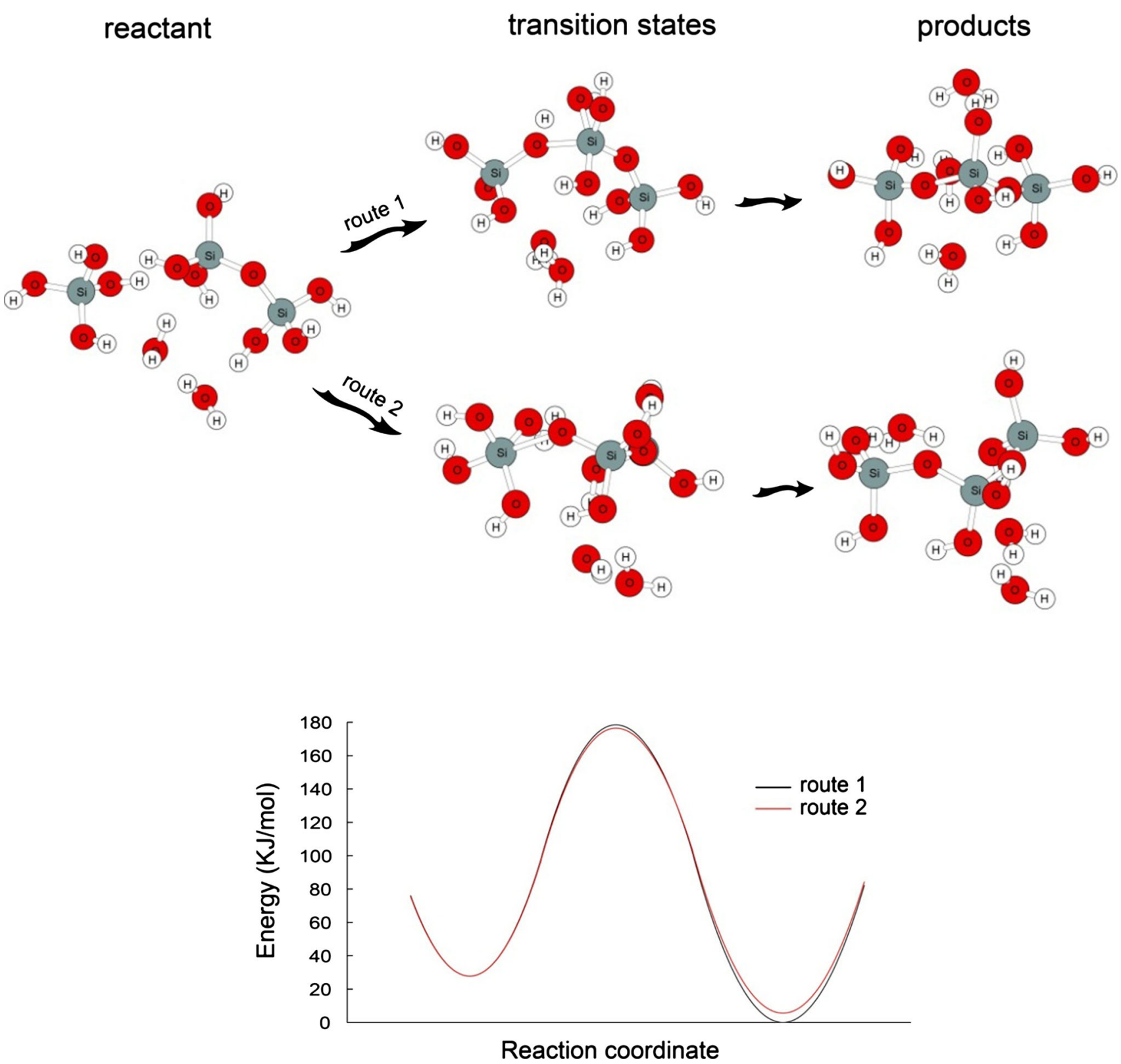

Fig. 4 B3LYP/6-311+G(2df,p) PES, with PCM solvation correction, for two routes of polymerization of monosilcic acid and dimer

Table 3 The KIEs for two routes to form trimer at ambient temperature

\begin{tabular}{lllll}
\hline & Activation energy & $\operatorname{RPFR}_{\text {reactant }}\left(25^{\circ} \mathrm{C}\right)$ & $\mathrm{RPFR}_{\mathrm{ts}}\left(25^{\circ} \mathrm{C}\right)$ & $\mathrm{KIE}$ \\
\hline Route 1 & $150.7 \mathrm{~kJ} / \mathrm{mol}$ & 1.069751 & 1.070235 & 0.999548 \\
Route 2 & $148.7 \mathrm{~kJ} / \mathrm{mol}$ & 1.069751 & 1.058512 & 1.010618 \\
\hline RPFR $_{\text {reactant }}$ and $\mathrm{RPFR}_{\mathrm{ts}}$ are the RPFR values of reactant and transition state, respectively &
\end{tabular}

\subsection{Si kinetic isotope fractionation for the formation of amorphous silica}

Previous theoretical works (He and Liu 2015; Rimstidt and Barnes 1980; McIntosh 2012; Nangia and Garrison 2008; Zhang and Liu 2014) all suggested that the polymerization of $\mathrm{H}_{4} \mathrm{SiO}_{4}$ molecules needed to overcome a rather high activation energy barrier. Besides, the $\mathrm{Si}$ kinetic isotope fractionation of about $-1.1 \%$ determined by Geilert et al. (2014) was identical to the $\mathrm{Si}$ equilibrium isotope fractionation between the monodentate ${ }^{1} \mathrm{~V}>\mathrm{Fe}_{2} \mathrm{OSi}(\mathrm{OH})_{3}$ and the $\mathrm{H}_{4} \mathrm{SiO}_{4}$ solution (He and Liu, 2015). So we suspected 


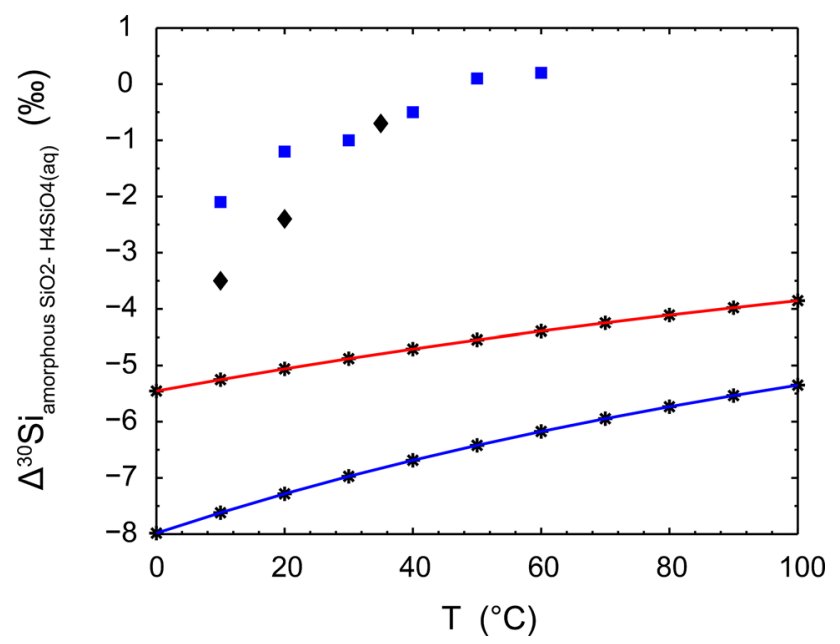

Fig. 5 Comparison between experimental data and calculated Si kinetic isotope fractionation during amorphous silica precipitation. The red line is the result of dimerization (He and Liu 2015); the blue line is the result of the polymerization of monosilicic acid and dimer; the blue squares are the experimental data of Geilert et al. (2014) and the black diamonds are the experimental data of Roerdink et al. (2015)

that the $\mathrm{Si}$ kinetic isotope fractionation determined by Geilert et al. (2014) represented a transient equilibrium, where the adsorbed $\mathrm{Si}$ was dominated by metastable monodentate ${ }^{1} \mathrm{~V}>\mathrm{Fe}_{2} \mathrm{OSi}(\mathrm{OH})_{3}$. The results of Roerdink et al. (2015) might have been contaminated by the diffusion of $\mathrm{H}_{4} \mathrm{SiO}_{4}$ from the solution to the surface of the seeds.

\section{4 $\mathrm{Si}$ isotope distributions in soil profile}

With the precise equilibrium $\mathrm{Si}$ isotope fractionation factors, distributions of the Si isotopes in the Earth's surface reservoirs can be constrained. For example, Ziegler et al. (2005) found that in the chronosequence of Hawaii soil, soil bulk $\delta^{30} \mathrm{Si}$ decreased to a more negative value from young to old soil in the lower soil layer $(30-100 \mathrm{~cm})$. Based on our theoretical calculations, we can provide reasonable explanations for their observations and predict a secular variation of the $\mathrm{Si}$ isotope in the soil profile.

As a response to the precipitation of amorphous allophane, which is formed following the dissolution of primary silicate minerals and is enriched with light $\mathrm{Si}$ isotopes, the bulk soil $\delta^{30} \mathrm{Si}$ will decrease. Since allophane is metastable, it will dissolve and transform into poorly crystalline minerals_-including clays_-in which the light $\mathrm{Si}$ isotope will continuously be enriched in products and the bulk $\delta^{30} \mathrm{Si}$ in the soil profile will gradually decrease. Meanwhile, Fe and Mn form sesqui-oxides and accumulate in old soils. Enhanced ${ }^{28} \mathrm{Si}$ adsorption on Fe-oxides drives the silicon isotope of the bulk soil to a more negative value (Delstanche et al. 2009). We can predict that bulk soil $\delta^{30} \mathrm{Si}$ in relation to the weathering degree has a concave pattern, with a minimum where allophane completely dissolves and the total amounts of sesqui-oxides and poorly crystalline minerals reaches their maximum.

When well crystalline clays precipitate from the pore solution under the isotope exchange equilibrium, bulk soil $\delta^{30} \mathrm{Si}$ increases and begins to level off. To substantiate our prediction we need more studies relevant to the crystallinity and $\mathrm{Si}$ isotope composition of clays in old soils. In conclusion, the decrease of $\delta^{30} \mathrm{Si}$ during kinetic precipitation will reasonably explain the stepwise decrease of $\delta^{30} \mathrm{Si}$ in the soil profile.

Similarly, the variation of ground water $\delta^{30} \mathrm{Si}$ with gradually enhanced water-rocks interaction can also be explained. Ground waters can effectively escape the perturbation of plants and will show distinct $\delta^{30} \mathrm{Si}$ variations during diagenesis. For example, Georg et al. (2009) determined the $\delta^{30} \mathrm{Si}$ of the ground water in the Navajo Sandstone aquifer and attributed the gradual decrease of the $\delta^{30} \mathrm{Si}$ along the flow path to the dissolution of kaolinite and amorphous silica, evidenced by the saturation index calculation. It should be noted that smectite also had precipitated from the ground water, which was shown by the saturation index calculation and electron microscopic characterization (Zhu et al. 2006). Smectite was found to be enriched in heavier silicon isotopes relative to the ground water, which matched our theoretical predictions. Therefore, the dissolution of poorly crystalline kaolinite and the precipitation of well crystalline smectite may cocontrol the observed $\delta^{30} \mathrm{Si}$ trend in ground water.

\subsection{Si isotope fractionations in plants}

In the metabolic process of plants, silicon (in the form of $\left.\mathrm{H}_{4} \mathrm{SiO}_{4}\right)$ is taken up by the root and accumulated in the xylem sap, where, even if the concentration of silicon is well above the saturation of the amorphous silica, polymerization does not occur. This point was confirmed by NMR experiments; the ${ }^{29} \mathrm{Si}$ NMR peak at approximately $-71 \mathrm{ppm}$ of xylem sap extraction was assigned to the 4-coordinated Si either as a monomer or as an organosilicon complex (Mitani et al. 2005; Sahai 2004). Polyol carbohydrates were suggested to be able to stabilize the Sibearing monomer species to a considerably elevated concentration in the solution (Kinrade et al. 1999, 2001). Moreover, the coordination number of $\mathrm{Si}$ in the organosilicon complexes increases with the $\mathrm{pH}$ value. The five-membered ring ${ }^{[5]} \mathrm{Si}$-disorbitol complex and the ${ }^{[6]} \mathrm{Si}$ trisorbitol complex had successfully reproduced the peaks near -102 and $-144 \mathrm{ppm}$ on the ${ }^{29} \mathrm{Si}$ NMR spectra and the heptet in the ${ }^{1} \mathrm{H}_{-}{ }^{29} \mathrm{Si}$ coupled spectra in solutions with high pH values (Kinrade et al. 1999, 2001; Kubicki and Heaney 2003; Sahai 2004). 
A unique $\delta^{30} \mathrm{Si}$ variation was observed in different $\mathrm{Si}$ accumulating plant organs including rice and bamboo: a concave $\delta^{30} \mathrm{Si}$ pattern for the sequence root $\rightarrow$ stem $\rightarrow$ branch $\rightarrow$ leaf with relative positive $\delta^{30} \mathrm{Si}$ in the shoots and the minimum of $\delta^{30} \mathrm{Si}$ in the stem (Ding et al. 2008, 2009). Based on the Rayleigh fractionation model, these unique $\delta^{30} \mathrm{Si}$ distributions observed by Ding and his co-authors were attributed to the different ratios of the biogenic ${ }^{28} \mathrm{Si}$ enriched silica gel to remnant the isotopically heavy $\mathrm{H}_{4} \mathrm{SiO}_{4}$ solution in different organs. However, rice and bamboo are not strictly closed systems for Si. In other words, Si can be excreted out of the rice and the bamboo through various mechanisms including guttation (Yamaji et al. 2008; Tian 2008).

Recently, a new transporter Lsi6, which can unload Si from the xylem sap and facilitates the subsequent intracellular transportation to silicon "pools", has been identified in the shoots (Yamaji et al. 2008). The molecular-level details of how Lsi6 transports the $\mathrm{Si}$ is still not clear. However, evidence shows that Lsi6 only transports $\mathrm{H}_{4} \mathrm{SiO}_{4}$, instead of the organosilicon complexes in the pool of xylem sap. With the help of the equilibrium $\mathrm{Si}$ isotope fractionation between $\mathrm{H}_{4} \mathrm{SiO}_{4(\mathrm{aq})}$ and the organosilicon complexes provided here, we can discuss the $\mathrm{Si}$ isotope fractionations associated with such a process. Because large $\mathrm{Si}$ isotope fractionations existed between $\mathrm{H}_{4} \mathrm{SiO}_{4(\mathrm{aq})}$ and the 5- or 6-coordinated organosilicon complexes, the $\mathrm{pH}$ value of the xylem-sap pool will be important for the Si isotope distributions in the plants. A higher $\mathrm{pH}$ value of the xylem-sap pool will let the transported Si become isotopically lighter.

\section{Conclusion}

Several important equilibrium $\mathrm{Si}$ isotope fractionation factors among minerals, organic molecules and the $\mathrm{H}_{4} \mathrm{SiO}_{4}$ solution are complemented to facilitate the explanation of the distributions of $\mathrm{Si}$ isotope in Earth's surface environments. Similar to quartz, precipitated minerals are enriched with heavier $\mathrm{Si}$ isotopes than other $\mathrm{Si}$-bearing species or compounds if they are at equilibrium. The order of $\mathrm{Si}$ heavy isotope enrichment is found to be albite $>$ kaolinite $>$ aqueous $\mathrm{H}_{4} \mathrm{SiO}_{4}>$ organosilicon complexes. Discrepancies related to field observations or previous theoretical calculations are carefully discussed. That the large kinetic isotope effect associated with the formation of amorphous quartz precursor results in the light $\mathrm{Si}$ isotope enrichment of field observed quartz is further confirmed.

Based on equilibrium $\mathrm{Si}$ isotope fractionation factors provided here, the distribution of $\mathrm{Si}$ isotopes in a few Earth's surface reservoirs can be constrained. For example, $\delta^{30} \mathrm{Si}$ variations in the soil can be predicted as a concave pattern in relation to weathering degree. Similarly, the precipitation of crystalline clay minerals and the dissolution of poorly crystalline kaolinite may explain the $\delta^{30} \mathrm{Si}$ variation in the ground water profile. Finally, equilibrium $\mathrm{Si}$ isotope fractionations between $\mathrm{H}_{4} \mathrm{SiO}_{4(\mathrm{aq})}$ and the 4-, 5or 6-coordinated organosilicon complexes can facilitate further discussion of the $\mathrm{Si}$ isotope distribution in plants.

Acknowledgments Y.L. is grateful for the funding support from the 973 Program (2014CB440904), CAS/SAFEA International Partnership Program for Creative Research Teams (Intraplate Mineralization Research Team, KZZD-EW-TZ-20) and Chinese NSF projects (41173023, 41225012, 41490635, 41530210). Hong-tao He thanks Dr. Guo-sheng Shao and Dr. Jun-yi Gong (China National Rice Research Institute) for their inspiring discussions about the excretion of Si from rice plants.

\section{References}

Balan E, Saitta AM, Mauri F, Calas G (2001) First-principles modeling of the infrared spectrum of kaolinite. Am Mineral 86:1321-1330

Basile-Doelsch I, Meunier JD, Parron C (2005) Another continental pool in the terrestrial silicon cycle. Nature 433:399-402

Becke AD (1993) A new mixing of hartreee-fork and local densityfunctional theories. J Chem Phys 98:1372-1377

Bigeleisen J, Mayer MG (1947) Calculation of equilibrium constants for isotopic exchange reactions. J Chem Phys 15:261-267

Bigeleisen J, Wolfsberg M (1958) Theoretical and experimental aspects of isotope effects in chemical kinetics. Adv Chem Phys $1: 15-76$

Bish DL (1993) Rietveld refinement of the kaolinite structure at 1.5 K. Clays Clay Miner 41:738-744

Bish D, Von Dreele R (1989) Rietveld refinement of non-hydrogen atomic positions in kaolinite. Clays Clay Miner 37:289-296

Delstanche S, Opfergelt S, Cardinal D, Elsass F, André L, Delvaux B (2009) Silicon isotopic fractionation during adsorption of aqueous monosilicic acid onto iron oxide. Geochemica et Cosmochimica Acta 73:923-934

Ding T, Tian S, Sun L, Wu L, Zhou J, Chen Z (2008) Silicon isotope fractionation between rice plants and nutrient solution and its significance to the study of the silicon cycle. Geochemica et Cosmochimica Acta 72:5600-5615

Ding T, Zhou J, Wan D, Chen Z, Wang C, Zhang F (2009) Silicon isotope fractionation in bamboo and its significance to the biogeochemical cycle of silicon. Geochemica et Cosmochimica Acta 72:1381-1395

Frisc MJ, Trucks GW, Schlegel HB, Scuseria GE, Robb MA, Cheeseman JR, Scalmani G, Barone V, Mennucci B, Petersson GA, Nakatsuji H, Caricato M, Li X, Hratchian HP, Izmaylov AF, Bloino J, Zheng G, Sonnenberg JL, Hada M, Ehara M, Toyota K, Fukuda R, Hasegawa J, Ishida M, Nakajima T, Honda Y, Kitao O, Nakai H, Vreven T, Montgomery JA, Peralta JE Jr, Ogliaro F, Bearpark M, Heyd JJ, Brothers E, Kudin KN, Staroverov VN, Keith T, Kobayashi R, Normand J, Raghavachari K, Rendell A, Burant JC, Iyengar SS, Tomasi J, Cossi M, Rega N, Millam JM, Klene M, Knox JE, Cross JB, Bakken V, Adamo C, Jaramillo J, Comperts R, Stratmann RE, Yazyev O, Austin AJ, Cammi R, Pomelli C, Ochterski JW, Martin RL, Morokuma K, Zakrzewski VG, Voth GA, Salvador P, Dannenberg JJ, Dapprich S, Daniels AD, Farkas O, Foresman JB, Ortiz JV, Cioslowski J, Fox DJ (2010) Gaussian 09 (Revision C.01). Gaussian Inc, Wallingford 
Geilert S, Vroon PZ, Roerdink DL, Van Cappellen P, van Bergen MJ (2014) Silicon isotope fractionation during abiotic silica precipitation at low temperature: influences from flow-through experiments. Geochemica et Cosmochimica Acta 142:95-114

Georg R, Reynolds B, West A, Burton K, Halliday A (2007) Silicon isotope variations accompanying basalt weathering in Iceland. Earth Planet Sci Lett 261:476-490

Georg R, Zhu C, Reynolds B, Halliday A (2009) Stable silicon isotopes of groundwater, feldspars, and clay coatings in the Navajo Sandstone aquifer, Black Mesa, Arizona, USA. Geochemica et Cosmochimica Acta 73:2229-2241

Gournis D, Lappas A, Karakassides M, Többens D, Moukarika A (2008) A neutron diffraction study of alkali cation migration in montmorillonites. Phys Chem Miner 35:49-58

Harlow GE, Brown GE (1980) Low albite: an X-ray and neutron diffraction study. Am Mineral 65:986-995

Hazen R, Finger L, Hemley R, Mao H (1989) High-pressure crystal chemistry and amorphization of $\alpha$-quartz. Solid State Commun 72:507-511

He H, Liu Y (2015) Si isotope fractionations during the precipitation of quartz and the adsorption of $\mathrm{H}_{4} \mathrm{SiO}_{4(\mathrm{aq})}$ on $\mathrm{Fe}$ (III)-oxyhydroxide surfaces. Chin J Geochem 34:459-468

Hughes H, Sondag F, Santos R, André L, Cardinal D (2013) The riverine silicon isotope composition of the Amazon Basin. Geochemica et Cosmochimica Acta 121:637-651

Kinrade SD, Del Nin JW, Schach AS, Sloan TA, Wilson KL, Knight CT (1999) Stable five-and six-coordinated silicate anions in aqueous solution. Science 285:1542-1545

Kinrade SD, Hamilton RJ, Schach AS, Knight CT (2001) Aqueous hypervalent silicon complexes with aliphatic sugar acids. J Chem Soc Dalton Trans 961-963

Kubicki J, Heaney P (2003) Molecular orbital modeling of aqueous organosilicon complexes: implications for silica biomineralization. Geochemica et Cosmochimica Acta 67:4113-4121

Liu Y (2013) On the test of a new volume variable cluster model method for stable isotopic fractionation of solids: Equilibrium $\mathrm{Mg}$ isotopic fractionations between minerals and solutions. Goldschmidt 2013 conference abstracts. 1632

McIntosh GJ (2012) A theoretical kinetic model of the temperature and $\mathrm{pH}$ dependent dimerization of orthosilicic acid in aqueous solution. Phys Chem Chem Phys 14:996-1013

McIntosh GJ (2013) Theoretical investigations into the nucleation of silica growth in basic solution part I- ab Initio studies of the formation of trimers and tetramers. Phys Chem Chem Phys 15:3155-3172

Méheut M, Schauble EA (2014) Silicon isotope fractionation in silicate minerals: insights from first-principles models of phyllosilicates, albite and pyrope. Geochemica et Cosmochimica Acta 134:137-154

Méheut M, Lazzeri M, Balan E, Mauri F (2007) Equilibrium isotopic fractionation in the kaolinite, quartz, water system: prediction from first-principles density-functional theory. Geochemica et Cosmochimica Acta 71:3170-3181

Méheut M, Lazzeri M, Balan E, Mauri F (2009) Structural control over equilibrium silicon and oxygen isotopic fractionation: a first-principles density-functional theory study. Chem Geol 258:28-37

Mitani N, Ma JF, Iwashita T (2005) Identification of the silicon form in xylem sap of rice (Oryza sativa L.). Plant Cell Physiol 46:279-283

Nangia S, Garrison BJ (2008) Reaction rates and dissolution mechanisms of quartz as a function of $\mathrm{pH}$. J Phys Chem A 112:2027-2033

Neder R, Burghammer M, Grasl T, Schulz H, Bram A, Fiedler S (1999) Refinement of the kaolinite structure from single-crystal synchrotron data. Clays Clay Miner 47:487-494

Opfergelt S, Delmelle P (2012) Silicon isotopes and continental weathering processes: assessing controls on $\mathrm{Si}$ transfer to the ocean. CR Geosci 344:723-738

Rastsvetaeva RK, Chukanov NV, Zadov AE (2009) Refined structure of afwillite from the northern Baikal region. Crystallogr Rep $54: 418-422$

Redlich O (1935) Eine allgemeine Beziehung zwischen den Schwingungsfrequenzen isotoper Molekeln. Zeitschrift Fur Physikalische Chemie-International J Res Phys Chem Chem Phys B 28:371-382

Rimstidt JD, Barnes HL (1980) The kinetics of silica-water reactions. Geochemica et Cosmochimica Acta 44:1683-1699

Roerdink DL, van den Boorn SHJM, Geilert S, Vroon PZ, van Bergen MJ (2015) Experimental constraints on kinetic and equilibrium silicon isotope fractionation during the formation of nonbiogenic chert deposits. Chem Geol 402:40-51

Sahai N (2004) Calculation of ${ }^{29} \mathrm{Si}$ NMR shifts of silicate complexes with carbohydrates, amino acids, and muhicarboxylic acids: potential role in biological silica utilization. Geochemica et Cosmochimica Acta 68:227-237

Savage PS, Georg RB, Williams HM, Burton KW, Halliday AN (2011) Silicon isotope fractionation during magmatic differentiation. Geochemica et Cosmochimica Acta 75:6124-6139

Tian X. (2008) Physio-ecology relationship between root pressure and bamboo species under low temperature stressed. Ph.D. Thesis, Nanjing Forestry University, Nanjing

Urey H.C. (1947) The thermodynamic properties of isotopic substances. J Chem Soc (London). 562-581

Yamaji N, Mitatni N, Ma JF (2008) A transporter regulating silicon distribution in rice shoots. Plant Cell 20:1381-1389

Zhang ST, Liu Y (2014) Molecular-level mechanisms of quartz dissolution under neutral and alkaline conditions in the presence of electrolytes. Geochem J 48:189-205

Zhu C, Veblen DR, Blum AE, Chipera SJ (2006) Naturally weathered feldspar surfaces in the Navajo Sandstone aquifer, Black Mesa, Arizona: electron microscopic characterization. Geochemica et Cosmochimica Acta 70:4600-4616

Ziegler K, Chadwick OA, Brzezinski MA, Kelly EF (2005) Natural variations of $\delta^{30} \mathrm{Si}$ ratios during progressive basalt weathering, Hawaiian Islands. Geochemica et Cosmochimica Acta 69:4597-4610 